LITERATURE REVIEW : PEMBERIAN POSISI SEMI FOWLER UNTUK MENURUNKAN FREKUENSI PERNAFASAN

PADA PASIEN ASMA

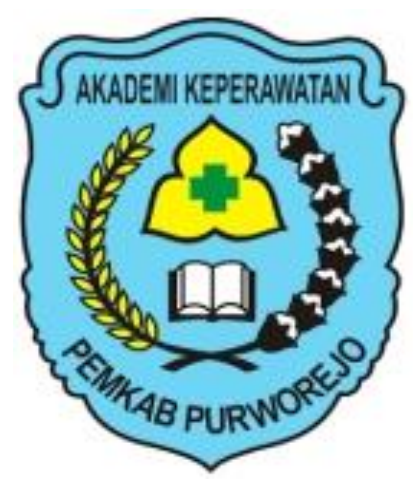

DISUSUN OLEH :

RIRIS AULIA PUTRI 18034 
LITERATURE REVIEW : PEMBERIAN POSISI SEMI FOWLER UNTUK MENURUNKAN FREKUENSI PERNAFASAN

PADA PASIEN ASMA

\section{NASKAH PUBLIKASI}

Diajukan sebagai salah satu syarat

Mendapatkan Gelar Ahli Madya Keperawatan (A.Md.Kep)

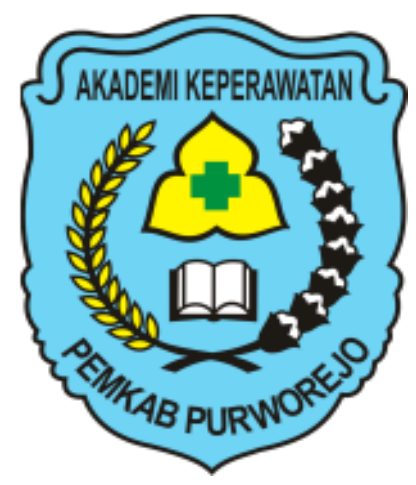

DISUSUN OLEH :

RIRIS AULIA PUTRI

18034

AKADEMI KEPERAWATAN PEMKAB PURWOREJO

2021 


\section{LEMBAR PENGESAHAN}

Naskah publikasi dengan judul "LITERATURE REVIEW : PEMBERIAN POSISI SEMI FOWLER UNTUK MENURUNKAN FREKUENSI PERNAFASAN PADA PASIEN ASMA" oleh Riris Aulia Putri (18034) telah disetujui dan diujikan di depan Dewan Penguji pada tanggal 20 Agustus 2021

Dewan Penguji :

Penguji I

Penguji II

Penguji III

Bayu Seto Rindi Atmojo,S.Kep.,Ns.,M.Kep NIDN : 0625118907
Wahyu Widodo.S.Kp.,Ns.o.M.Kep

NIDN : 0609087301

Mengetahui,

Akademi Keperawatan Pemkab Purworejo

Direktur
Ahmad Muzaki,S.Kep.oNs..M.Kep

NIDN : 0622038902

Wahidin S.Kep.,Ns,M.Kep

NIDN : 0622038601 


\title{
LITERATURE REVIEW : PEMBERIAN POSISI SEMI FOWLER UNTUK MENURUNKAN FREKUENSI PERNAFASAN PADA PASIEN ASMA
}

\author{
Riris Aulia Putri ${ }^{1}$, Ahmad Muzaki², Wahyu Widodo³ \\ Mahasiswa Akademi Keperawatan Pemkab Purworejo ${ }^{1}$ \\ Dosen Akademi Keperawatan Pemkab Purworejo ${ }^{2}$ \\ Dosen Akademi Keperawatan Pemkab Purworejo ${ }^{3}$
}

Purworejo, (0275)3140576

Email: riris2203@gmail.com

\begin{abstract}
ABSTRAK
Latar Belakang: Asma adalah suatu kelainan berupa inflamasi kronik pada saluran pernafasan yang dapat menyebabkan hiperaktivitas bronkus terhadap berbagai rangsangan yang dapat menimbulkan suatu gejala seperti mengi, batuk, sesak nafas, dan dada terasa berat terutama pada saat malam atau dini hari. Posisi semi fowler merupakan suatu posisi tempat tidur dimana posisi kepala dan tubuh lebih ditinggikan 15 derajat hingga 45 derajat, pada pemberian posisi semi fowler dilakukan sebagai salah satu cara untuk membantu mengurangi sesak nafas pada pasien asma. Pernafasan merupakan suatu peristiwa menghirup udara dari luar yang mengandung oksigen ke dalam tubuh dan menghembuskan udara yang banyak mengandung karbondioksida selagi tersisa dan oksidasi yang keluar dari tubuh. Tujuan: Untuk mengetahui efektifitas posisi semi fowler untuk menurunkan frekuensi pernafasan pada pasien asma. Metode: Penulis menggunakan metode literature review penelusuran melalui database google scholar dengan menggunakan kata kunci "posisi semi fowler + frekuensi pernafasan + asma". Artikel ilmiah yang dianalisis adalah yang dipublikasikan sejak tahun 2016 sampai dengan 2020 yang diakses fulltext dalam format pdf. Hasil: Hasil penelitian ini menunjukkan bahwa pemberian posisi semi fowler dapat berpengaruh untuk menurunkan frekuensi pernafasan pada pasien asma. Kesimpulan: Berdasarkan dari kelima jurnal yang telah disajikan oleh penulis, dapat disimpulkan bahwa posisi semi fowler efektif untuk menurunkan frekuensi pernafasan pada pasien asma.
\end{abstract}

Kata kunci : Posisi semi fowler, frekuensi pernafasan, asma

\section{ABSTRACT}

Background: Asthma is a disorder in the form of chronic inflammation of the respiratory tract that can cause bronchial hyperactivity to various stimuli that can cause symptoms such as wheezing, coughing, shortness of breath, and chest tightness, especially at night or early morning. The semi-fowler position is a bed position where the head and body are elevated 15 degrees to 45 degrees, the semi-fowler position is given as a way to help reduce shortness of breath in asthmatic patients. Breathing is an 
event of inhaling air from the outside containing oxygen into the body and exhaling air containing a lot of carbon dioxide while remaining and oxidizing out of the body. Objective: To determine the effectiveness of the semi-Fowler's position to reduce respiratory rate in asthma patients. Methods: The author uses the literature review method of searching through the Google Scholar database using the keywords "semifowler's position + respiratory frequency + asthma". The scientific articles analyzed are those published from 2016 to 2020 which are accessed in full text in pdf format.. Results: The results of this study indicate that the provision of a semi-Fowler's position can have an effect on reducing respiratory frequency in asthmatic patients. Conclusion: Based on the five journals that have been presented by the authors, it can be concluded that the semi-fowler position is effective for reducing respiratory frequency in asthmatic patients.

\section{Keywords: Semi-Fowler's position, respiratory rate, asthma}

\section{Pendahuluan}

Asma adalah masalah kesehatan di seluruh dunia yang mempengaruhi negara-negara industri dan berkembang, menurut Inisiatif Global untuk Asma. Sesak napas, mengi, dada sesak, batuk yang semakin parah, dan aliran udara ekspirasi terbatas adalah tanda-tanda penyakit ini, yang ditandai dengan peradangan kronis pada saluran udara (Mark et al., 2016). Menurut Gina (2015). Asma adalah penyakit inflamasi kronis pada saluran napas yang menyebabkan hiperaktivitas bronkus sebagai respons terhadap berbagai rangsangan, sehingga menimbulkan gejala seperti mengi, batuk, sesak napas, dan sesak dada, terutama pada malam hari atau dini hari, dan umumnya reversibel dengan atau tanpa pengobatan. Kementerian Kesehatan Republik Indonesia, 2009. Asma telah menyebar ke seluruh dunia, menyerang orang dari segala usia.

Menurut Kumoro (2008) Asma sering menyerang pada malam hari, tetapi pada kasus yang parah, serangan asma dapat menyerang kapan saja. Inspirasi pasien asma menjadi singkat dan dangkal, mengakibatkan sianosis, penampilan wajah pucat dan lemah, dan keringat berlebihan. Penderita asma akan merasa cemas dan berusaha untuk bernapas sekeras mungkin karena thoraxnya akan dibatasi pergerakannya (Kumoro 2008).

Menurut WHO (2018) di Jawa Tengah terdapat data sebanyak 91.161 orang yang terkena asma (dikutip dari data riskesdas,2018). Sedangkan di Kota 
Purworejo terdapat 1.896 orang yang terkena penyakit asma.

Salah satu intervensi atau rencana yang akan dilakukan pada pasien asma untuk memaksimalkan ventilasi paru adalah melalui latihan pernapasan diafragma, yang dilakukan dengan inspirasi maksimal melalui hidung dan dapat menurunkan kerja otot-otot pernapasan, sehingga meningkatkan perfusi alveolus dan pertunjukan. Identifikasi difusi oksigen yang dapat meningkatkan saturasi oksigen dan meningkatkan kadar oksigen di paruparu (Zega et al dalam Mayuni et al, 2015). Selanjutnya, untuk mengatasi masalah pola pernapasan yang tidak efisien, intervensi atau strategi yang akan diterapkan adalah menawarkan pengaturan posisi bagi penderita asma (Black \& Hawks, 2010). ${ }^{\circ}$

Posisi semi fowler adalah salah satu di mana tempat tidur, kepala, dan batang tubuh semua diangkat $15^{\circ}$ sampai $45^{\circ}$ derajat. Low fowler adalah nama lain untuk postur ini, yang umumnya ditinggikan 30 derajat (Kozier dan Erb's, 2016). Pada pasien asma, Fowler semipostur telah digunakan untuk membantu meminimalkan sesak napas. Frekuensi pernapasan, yang khas pada 16-24 kali per menit, menunjukkan kemanjuran langkah-langkah ini (Ruth, 2002).

Hasil penelitian yang dilakukan oleh Muzaki \& Ani, (2020) menunjukkan hasil bahwa penerapan posisi semi fowler (posisi duduk $45^{\circ}$ ) selama 3×24 jam sesuai dengan SOP membantu mengurangi sesak nafas dan membantu mengoptimalkan RR pada klien sehingga masalah ketidakefektifan pola nafas dapat teratasi (Muzaki \& Ani, 2020).

Berdasarkan Latar belakang diatas Maka penulis tertarik untuk menyusun Literature Review dengan judul "Literature Review: Pemberian Posisi Semi Fowler Untuk Menurunkan Frekuensi Pernafasan Pada Pasien Asma".

\section{Metode Penelitian}

Metode penelitian menggunakan literatur review, sebagai mengumpulkan dan menganalisis sebanyak 5 artikel jurnal penelitian mengenai penerapan posisi semi fowler. Pencarian artikel jurnal menggunakan pendekatan data (data bse) Google scholar dengan kata kunci posisi semi fowler + frekuensi pernafasan + asma. artikel yang dipilih diterbitkan antara tahun 2016 dan 2020 
dan tersedia dalam bentuk teks lengkap

dalam format pdf dan bahasa Indonesia.

Analisa data dilakukan dengan cara

mendiskusikan dan meringkas literature

kemudian membandingkan beberapa

literature dan selanjutnya dituangkan

dalam pembahasan. Untuk mereview seluruh literature bisa melakukannya dengan bebrapa cara : Mencari kesamaan (simmiliarily), Mencari ketidaksamaan (contrast), Memberikan, pandangan (criticize), Membandingkan (compare), Meringkas (summarize)

\section{Hasil}

Hasil analisis literatur review ini disajikan dalam Tabel 1.

Tabel 1. Hasil Rekapitulasi Artikel Literatur Review

\begin{tabular}{|c|c|c|c|c|}
\hline No & Judul & Metode Penelitian & Subjek Penelitian & Hasil \\
\hline 1 & $\begin{array}{l}\text { Posisi semi } \\
\text { fowler } \\
\text { menurunkan } \\
\text { frekuensi nafas } \\
\text { pasien asma } \\
\text { bronchial }\end{array}$ & $\begin{array}{l}\text { Penelitian Quasi } \\
\text { Experiment dengn } \\
\text { menggunakan } \\
\text { rancangan One } \\
\text { Group Pre test-Post } \\
\text { test }\end{array}$ & 20 responden & $\begin{array}{l}\text { Ada pengaruh pemberian } \\
\text { posisi semi fowler terhadap } \\
\text { penurunan frekuensi } \\
\text { pernafasan dengan nilai p } \\
\text { value } 0,001 \text { dengan rata-rata } \\
\text { sebelum diberikan intervensi } \\
\text { pemberian posisi semi } \\
\text { fowler yaitu } 8,729 \text { dan rata- } \\
\text { rata sesudah dilakukan } \\
\text { intervensi pemberian posisi } \\
\text { semi fowler 2,306. }\end{array}$ \\
\hline 2 & $\begin{array}{lr}\text { Pengaruh nafas } \\
\text { dalam dan posisi } \\
\text { terhadap saturasi } \\
\text { oksigen dan } \\
\text { frekuensi nafas } \\
\text { pada pasien } \\
\text { asma }\end{array}$ & $\begin{array}{l}\text { Penelitian ini } \\
\text { menggunakan } \\
\text { penelitian Quasi } \\
\text { Ekperiment dengan } \\
\text { rancangan pretest- } \\
\text { posttest with control } \\
\text { group. sampel } \\
\text { diambil } \\
\text { menggunakan } \\
\text { consequtive } \\
\text { sampling }\end{array}$ & $\begin{array}{l}\text { Setiap kelompok } \\
15 \text { orang dan } \\
\text { keselurahan } \\
\text { terdapat } 30 \text { orang }\end{array}$ & $\begin{array}{l}\text { Ada pengaruh terhadap } \\
\text { terhadap pemberian posisi } \\
\text { semi fowler pada pasien } \\
\text { asma terhadap pengaruh } \mathrm{RR} \\
\text { dengan nilai p value } 0,001\end{array}$ \\
\hline 3 & $\begin{array}{lr}\text { Efektifitas } & \text { posisi } \\
\text { semi } & \text { fowler } \\
\text { terhadap } & \\
\text { penurunan } & \text { sesak } \\
\text { nafas } & \text { pada } \\
\text { pasien } & \text { asma } \\
\text { bronchiale } & \text { di } \\
\text { RSUD } & \text { Kota } \\
\text { Kendari } & \end{array}$ & $\begin{array}{l}\text { Penelitian ini } \\
\text { menggunakan } \\
\text { penelitian Pre } \\
\text { Eksperiment dengan } \\
\text { pendekatan the one- } \\
\text { group pretest- } \\
\text { posttest design, } \\
\text { dengan cara } \\
\text { accidental sampling }\end{array}$ & 17 responden & $\begin{array}{l}\text { Ada pengaruh terhadap } \\
\text { pemberian terhadap } \\
\text { pemberian posisi semi } \\
\text { fowler berbengaruh } \\
\text { menurunkan sesak nafas } \\
\text { pada pasien asma bronchial } \\
\text { dengan nilai p value }<0,001\end{array}$ \\
\hline
\end{tabular}




\begin{tabular}{|c|c|c|c|c|}
\hline No & Judul & Metode Penelitian & Subjek Penelitian & Hasil \\
\hline 4 & $\begin{array}{l}\text { Pengaruh } \\
\text { pemberian posisi } \\
\text { semi fowler } \\
\text { terhadap } \\
\text { respiration rate } \\
\text { pada pasien } \\
\text { asma bronchial } \\
\text { di puskesmas } \\
\text { Air Upas } \\
\text { Ketapang }\end{array}$ & $\begin{array}{l}\text { Penelitian ini } \\
\text { merupakan } \\
\text { penelitian Quasi } \\
\text { Eksperimental } \\
\text { dengan pre and post } \\
\text { test with control } \\
\text { group design. }\end{array}$ & 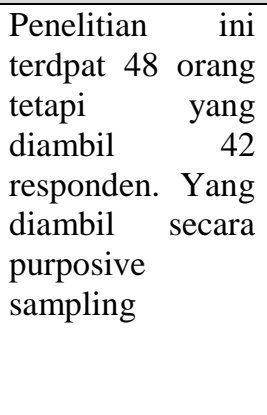 & $\begin{array}{l}\text { Ada pengaruh terhadap } \\
\text { pemberian posisi semi } \\
\text { fowler pada pasien asma } \\
\text { bronchial untuk menurunkan } \\
\text { respiration rate } \quad \text { di } \\
\text { puskesmas air upas } \\
\text { ketapang dengan nilai p } \\
\text { value } 0,000\end{array}$ \\
\hline 5 & $\begin{array}{l}\text { The effect of } \\
\text { semi fowler } \\
\text { position on the } \\
\text { stability of } \\
\text { breathing among } \\
\text { asthma patients } \\
\text { at ratu zalecha } \\
\text { hospital } \\
\text { martapura }\end{array}$ & $\begin{array}{l}\text { This study used a } \\
\text { pre-experimental } \\
\text { study design. }\end{array}$ & $\begin{array}{l}\text { Using simple } \\
\text { random sampling } \\
\text { technique with } \\
30 \text { respondents }\end{array}$ & $\begin{array}{l}\text { There was a significant } \\
\text { effect between before and } \\
\text { after of giving semi-fowler } \\
\text { position to the stability of to } \\
\text { breathings in asthma } \\
\text { patients at Ratu Zalecha } \\
\text { Martapura Hospital }(0,000) \text {. }\end{array}$ \\
\hline
\end{tabular}

\section{Pembahasan}

Dari kelima artikel jurnal telah dilakukan review terdapat persamaan dan perbedaan pada masing-masing penelitian. Metode penelitian yang sama dilakukan oleh Sahrudi \& Mirza Satria (2020), Anita

Yulia dkk (2019), Luhur Arifian \& Joko Kismanto (2018) ketiganya menggunakan metode penelitian Quasi Eksperimental. Sedangkan penelitian dari Muhaimin Sarani (2016) dan Insana Maria dkk (2019) menggunakan metode penelitian pre eksperiment.

Penelitian yang digunakan merupakan jenis penelitian eksperimen (quasi eksperimental design). Menurut
Sugiyono (2015 : 114) eksperimen semu adalah suatu penelitian yang mendekati eksperimen yang sesungguhnya. Penelitian ini bertujuan untuk menguji secara langsung terhadap pengaruh suatu variabel satu dengan variable yang lain dan untuk menguji hipotesis hubungan sebab dan akibat. Desain eksperimen ini mempunyai kelas eksperimen dan kelas kontrol, tetapi kelas kontrol tidak dapat berfungsi sepenuhnya untuk mengontrol variabel dari luar yang dapat mempengaruhi pelaksanaan eksperimen. Disebut dengan Pre Experimental Design karena desain ini belum termasuk eksperimen yang sungguhsungguh, karena masih terdapat variabel 
dari luar yang ikut berpengaruh atas terbentuknya variabel dependen. Jadi eksperimen yang merupakan variabel dependen itu bukan hanya dipengaruhi oleh variabel independen. Hal tersebut dapat terjadi ketika tidak adanya variabel kontrol, dan sampel tidak dipilih secara random. Ada beberapa macam bentuk pre-experimental designs, yaiitu: one-Shot Case Study, One-Group Pretest-Posttest Design dan Intact-Group Comparison.

Dari kelima artikel jurnal ada beberapa penggunaan rancangan, Sahrudi dkk (2020) menggunakan rancangan one group pre test post test, Anita Yulia dkk (2019) dan Luhur Arifian dkk (2018) menggunakan rancangan pre test post test with control group, Muhaimin Sarani (2016) menggunakan teknik pendekatan the one group pre test post test, Insana Maria dkk (2019) menggunakan pre-post test. Sedangkan dalam pengambilan sampel yang dilakukan oleh Anita Yulia dkk (2019) menggunakan teknik non probability yaitu dengan consecutive sampling, Luhur Arifin dkk (2018) menggunakan teknik purpose sampling, Insana Maria dkk (2019) menggunakan teknik simple random dan menggunakan desain pre-post test.

"One Groups Pretest-Posttest Design", merupakan desain penelitian yang terdapat pretest sebelum diberikan tindakan dan posttest setelah diberikan tindakan. Dengan ini dapat diketahui akan lebih akurat, karena dapat membandingkan sebelum diberikan tindakan (Sugiyono, 2001: 64). Purposive sampling, merupakan teknik pemilihan sampel dalam peninjauan tertentu (Sugiyono, 2006: 61). Simple Random Sampling yaitu pengambilan sampel dengan cara acak tanpa memperhatikan level yang ada dalam anggota populasi (Nursalam, 2003). Consecutive sampling yaitu pemilihan sample dengan cara menetapkan subjek yang memenuhi kriteria penelitian dimasukkan dalam penelitian sampai kurun waktu tertentu, sehingga jumlah responden dapat terpenuhi (Nursalam, 2003).

Jumlah sampel yang digunakan pada penelitian Sahrudi dkk (2020) menggunakan 20 responden, Anita Yulia dkk (2019) menggunakan 30 responden, Muhaimin Sarani (2016) menggunakan 17 responden, Luhur Arifin (2018) menggunakan 42 responden, Insana 
Maria dkk (2019) menggunakan 30 responden, Insana Maria dkk (2019) menggunakan 30 responden.

Sedangkan, instrument yang digunakan untuk mengukur atau membandingkan frekuensi pernafasan pada kelima jurnal berbeda, tiga jurnal menggunakan lembar observasi untuk menilai stabilitas pernafasan sebelum dan sesudah diberikan intervensi, sedangkan dua jurnal berikutnya dari Sahrudi, Mirza Satria (2020) dan Muhaimin Sarani (2016) tidak menjelaskan intrumen apa yang digunakan dalam penelitianya. Dari kelima jurnal yang sudah dilakukan review oleh penulis dapat disimpulkan bahwa pemberian posisi semi fowler berpengaruh terhadap penurunan frekuensi pernafasan pada pasien asma.

Dari kelima artikel jurnal yang didapat, penulis menyimpulkan bahwa kelima jurnal tersebut berhasil dalam pemberian intervensi posisi semi fowler, sehingga frekuensi pernafasan pasien asma dapat menurun. Hal itu, dibuktikan pada hasil penelitian yang dilakukan Safitri, Andriyani (2011) dan Sulastri, Ismonah, Wulandari (2015) bahwa ada efek dalam pemberian posisi semi fowler dengan kepala ditinggikan 45 derajat dapat menurunkan sesak nafas secara efektif karena adanya efek gaya gravitasi sehingga dapat membantu mengurangi tekanan pada abdomen dan meningkatkan pengembangan paru.

\section{Kesimpulan}

a. Posisi semi-Fowler diterapkan pada setiap penelitian di lima jurnal yang telah dievaluasi, dan pengaruh postur semi-Fowler pada pasien asma diterapkan di kelima jurnal.

b. Penulis juga sudah mengetahui proses penyusunan literature review dengan langkah-langkah antara lain pemilihan topik, penentuan keyword, dan analisis data.

c. Setelah melakukan penyusunan karya tulis ilmiah dengan teknik literature review maka penulis telah mengetahui cara mencari dan menganalisis jurnal yang telah didapat.

d. Dari kelima artikel jurnal telah dilakukan review terdapat persamaan dan perbedaan pada masing-masing penelitian. Metode penelitian yang sama dilakukan oleh Sahrudi \& Mirza Satria (2020), Anita Yulia dkk (2019), Luhur Arifian \& Joko Kismanto (2018) 
ketiganya menggunakan metode penelitian Quasi Eksperimental. Sedangkan penelitian dari Muhaimin Sarani (2016) dan Insana Maria dkk (2019) menggunakan metode penelitian pre eksperiment.

\section{Ucapan Terimakasih}

Penulis mengucapkan terimakasih kepada Direktur Akper Pemkab Purworejo serta Pembimbing I dan II yang telah memberikan dukungan, masukan dan bimbingan dalam penyelesaian publikasi ini.

\section{Daftar Pustaka}

(2015). Metode Penelitian Kombinasi (Mix Methods). Bandung: Alfabeta. 2006.Metode Penelitian Kuantitatif, Kualitatif dan R \& D.Bandung:Alfabeta.

Black,J.M. \& Hawks,J.H.(2010). Medical Surgical Nursing : Clinical Management for Positive Outcomes, Singapore: Elsevier
Gina.(2015). Global Strategi for asthma management and prevention

Kozier \& Erb's, 2016. Fundamentals of Nursing Concepts, proces and praktice Tenth Edition .United States of America : Julie Levin Alexander

Kumoro, D. 2008., Pengaruh Pemberian Senam Asma Terhadap Frekwensi Kekambuhan Asma Bronkial (Skripsi). Surakarta: Universitas Muhammadiyah Surakarta.

Mark et.al.2016. Global Strategy for Asthma Management and Preventation. dilihat 3 februari 2021, http://www.ginasthma.com

Muzaki, A., \& Ani, Y. (2020). Penerapan Posisi Semi Fowler Terhadap Ketidakefektifan Pola Nafas Pada Pasien Congestive Heart Failure (Chf). Nursing Science Journal (NSJ), 1(1), 1924. https://doi.org/10.53510/nsj.vli1. 16

Nursalam (2003). Konsep dan Penerapan Metodologi Penelitian 
Ilmu Keperawatan Pedoman

Skripsi, Tesis dan Instrumen

Penelitian Keperawatan. Jakarta :

Salemba Medika.

Ruth, 2002, Fundamental of Nursing

Human Healt And Function,

Jakarta : EGC

Sistem Pernafasan. Edisi 2. Jakarta :

Salemba Medika

Sugiyono, 2001. Metode Penelitian,

Bandung: CV Alfa Beta. 
